\title{
Alcohol-Related Injuries: Evidence for the Prevention Paradox
}

\author{
Maria C. Spurling, $M D^{1}$ \\ Daniel C. Vinson, MD, MSPH ${ }^{2}$ \\ ${ }^{1}$ School of Medicine, University \\ of Missouri-Columbia, Columbia, Mo \\ ${ }^{2}$ Department of Family and Community \\ Medicine, University of Missouri-Columbia, \\ Columbia, Mo
}

\begin{abstract}
PURPOSE The risk of an injury increases exponentially with alcohol consumption on a given occasion, but the conclusion that alcohol-related injuries are attributable primarily to heavy drinking may or may not be correct. The prevention paradox states that a large number of people at small risk may contribute more cases of a particular condition than a smaller number of people who are individually at greater risk. We sought to determine the extent to which the prevention paradox applies in the relationship between alcohol consumption and injury.
\end{abstract}

METHODS We conducted a population-based case-control and case-crossover study in all 3 emergency departments in Boone County, Mo. Data were collected from 2,517 patients with an acute injury and 1,856 age- and sex-matched controls selected by random digit dialing.

RESULTS The population attributable fraction (PAF) associated with drinking in the 6 hours before injury - the proportion of injuries that would not have occurred in the absence of drinking - was $10.6 \%$ in case-crossover analysis and $8.5 \%$ in casecontrol analysis. The PAF that was due to what is usually considered nonhazardous alcohol consumption (fewer than 5 drinks for men, fewer than 4 for women) was $4.5 \%$ in case-crossover analysis and $3.1 \%$ in case-control analysis. The PAF that was due to alcohol dependence was $4.0 \%$.

CONCLUSIONS Injury is associated more with an occasion of alcohol consumption than with alcohol dependence. A substantial proportion of the PAF that is due to an occasion of alcohol consumption is from what are usually considered low-risk quantities.

Ann Fam Med 2005;3:47-52. DOI: 10.1370/afm.243.

\section{INTRODUCTION}

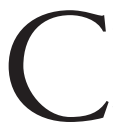
onsuming as few as 2 alcoholic drinks increases the risk of an injury, and the risk rises exponentially with consumption above that amount. ${ }^{1}$ For an individual, risk rises with consumption. For a society, however, the total number of injuries attributable to drinking may not follow that exponential curve.

The prevention paradox states, "A large number of people at a small risk may give rise to more cases of disease than the small number who are at a high risk." ${ }^{2,3}$ For coronary artery disease, for example, the population attributable fraction (PAF) — the proportion of disease that would be avoided in the absence of a particular risk factor - is greater for cholesterol levels between 200 and $250 \mathrm{mg} / \mathrm{dL}$ than for levels higher than $300 \mathrm{mg} / \mathrm{dL}$ because the former are more common. ${ }^{4}$ Considering alcohol, the prevention paradox would suggest that alcohol-related problems in a population come more from moderate drinkers than from heavy drinkers because there are so many more moderate drinkers, even though moderate drinkers are individually at lower risk of adverse outcomes than heavy drinkers.

In 1986, Kreitman ${ }^{5}$ reported evidence that the prevention paradox applies to alcohol, noting that most individuals with alcohol-related problems consumed less than the thresholds commonly used to define 
hazardous drinking on average. In an Australian population-based survey, Stockwell and colleagues ${ }^{6}$ also found support for the prevention paradox, with only $25 \%$ of the 67 individuals who reported intoxicationrelated harm exceeding the threshold for hazardous drinking on average. But the phrase "on average" here is key. Stockwell et al also reported evidence that challenged the prevention paradox. When they defined high-risk using per occasion thresholds, $87 \%$ of those 67 individuals reported hazardous drinking on the day the event occurred. Gmel et $\mathrm{al}^{7}$ and even Kreitman ${ }^{5}$ reported similar findings.

Assessment of per-occasion alcohol consumption, however, has been limited. Kreitman and Gmel et al looked at typical frequency of heavy drinking, not at drinking on the day the event occurred. Stockwell and his colleagues did, but framed the question about injury in the context of a "problem of intoxication." They inquired only about injuries "partly due to drinking," and examined hazardous alcohol consumption using only a dichotomous variable. ${ }^{6}$
Our recently published case-control study of alcohol and the risk of injury ${ }^{1}$ provides data that allow us to determine to what extent the prevention paradox applies, examining consumption in the hours before injury as a continuous variable.

\section{METHODS}

\section{Participants}

Case patients were acute injury patients aged 18 years or older cared for in 1 of the 3 emergency departments in Boone County, Mo, between February 1998 and March 2000 (Table 1). Research staff worked during systematically selected shifts to sample each day of the week and hour of the day equally. Case patients recruited during these times $(n=2,161)$ are labeled "from covered shifts." To include more patients with severe injuries, we recruited 356 inpatients admitted from the emergency department during times not covered by study interviewers. Of eligible patients who were approached, $86 \%$ participated.

\section{Table 1. Description of Participants}

\begin{tabular}{|c|c|c|c|c|c|c|}
\hline Characteristic & \multicolumn{2}{|c|}{$\begin{array}{c}\text { All Cases } \\
(\mathrm{N}=2,517) \\
\text { No. }(\%)\end{array}$} & \multicolumn{2}{|c|}{$\begin{array}{l}\text { Cases From Covered Shifts } \\
(\mathrm{n}=2,161) \\
\text { No. }(\%)\end{array}$} & \multicolumn{2}{|c|}{$\begin{array}{l}\text { Community Controls } \\
(\mathrm{n}=1,856) \\
\text { No. }(\%)\end{array}$} \\
\hline \multicolumn{7}{|l|}{ Sex } \\
\hline Women & \multicolumn{2}{|c|}{$1,085(43.1)$} & \multicolumn{2}{|c|}{$967(44.7)$} & \multicolumn{2}{|c|}{908 (48.9) } \\
\hline Men & \multicolumn{2}{|c|}{$1,432(56.9)$} & \multicolumn{2}{|c|}{$1,194(55.3)$} & \multicolumn{2}{|c|}{$948(51.1)$} \\
\hline \multicolumn{7}{|l|}{ Age, years } \\
\hline 18 to 20 & \multicolumn{2}{|c|}{$419(16.6)$} & \multicolumn{2}{|c|}{$379(17.5)$} & \multicolumn{2}{|c|}{$201(10.8)$} \\
\hline 21 to 29 & \multicolumn{2}{|c|}{$716(28.4)$} & \multicolumn{2}{|c|}{$636(29.4)$} & \multicolumn{2}{|c|}{$560(30.2)$} \\
\hline 30 to 44 & \multicolumn{2}{|c|}{$761(30.2)$} & \multicolumn{2}{|c|}{$658(30.4)$} & \multicolumn{2}{|c|}{$616(33.2)$} \\
\hline 45 to 64 & \multicolumn{2}{|c|}{$421(16.7)$} & \multicolumn{2}{|c|}{$325(15.0)$} & \multicolumn{2}{|c|}{$329(17.7)$} \\
\hline 65 and over & \multicolumn{2}{|c|}{$200(7.9)$} & \multicolumn{2}{|c|}{$163(7.5)$} & \multicolumn{2}{|c|}{$150(8.1)$} \\
\hline Alcohol use disorders & \multicolumn{2}{|c|}{$497(19.7)$} & \multicolumn{2}{|c|}{$433(20.0)$} & \multicolumn{2}{|c|}{$307(16.5)$} \\
\hline Alcohol abuse & \multicolumn{2}{|c|}{$293(11.6)$} & \multicolumn{2}{|c|}{$255(11.8)$} & \multicolumn{2}{|c|}{$232(12.5)$} \\
\hline Alcohol dependence & \multicolumn{2}{|c|}{$204(8.1)$} & 178 & 8.2) & & \\
\hline Location of residence & & & & & & \\
\hline Rural & 723 & (28.7) & 478 & 22.1) & 430 & 3.2) \\
\hline Urban & 1,794 & (71.3) & 1,683 & 77.9) & 1,426 & $6.8)$ \\
\hline $\begin{array}{l}\text { Alcohol consumed in } 6 \\
\text { before injury or, amo } \\
\text { controls, the matched }\end{array}$ & & & & & & \\
\hline Any & 352 & $(14.0)$ & 266 & 12.3) & & \\
\hline $\begin{array}{l}\text { Drinks in } \\
\text { 6-h Window } \\
\text { No. }\end{array}$ & $\begin{array}{c}\text { Men } \\
(\mathrm{n}=1,432) \\
\text { No. }(\%)\end{array}$ & $\begin{array}{c}\text { Women } \\
(\mathrm{n}=1,085) \\
\text { No. }(\%)\end{array}$ & $\begin{array}{c}\text { Men } \\
(n=1,194) \\
\text { No. }(\%)\end{array}$ & $\begin{array}{l}\text { Women } \\
(n=967) \\
\text { No. }(\%)\end{array}$ & $\begin{array}{c}\text { Men } \\
(\mathrm{n}=948) \\
\text { No. }(\%)\end{array}$ & $\begin{array}{l}\text { Women } \\
(\mathrm{n}=908) \\
\text { No. }(\%)\end{array}$ \\
\hline 1 drink & $34(2.4)$ & $17(1.6)$ & $29(2.4)$ & $16(1.7)$ & $23(2.4)$ & $18(2.0)$ \\
\hline 2 drinks & $38(2.7)$ & $14(1.3)$ & $23(1.9)$ & $12(1.2)$ & $14(1.5)$ & $6(0.7)$ \\
\hline 3 drinks & $32(2.2)$ & $13(1.2)$ & $21(1.8)$ & $9(0.9)$ & $11(1.2)$ & $3(0.3)$ \\
\hline 4 drinks & $32(2.2)$ & $8(0.7)$ & $25(2.1)$ & $6(0.6)$ & $8(0.8)$ & $0(0)$ \\
\hline 5 or 6 drinks & $52(3.7)$ & $26(2.4)$ & $40(3.4)$ & $21(2.2)$ & $5(0.5)$ & $1(0.1)$ \\
\hline 7 or more drinks & $68(4.8)$ & $18(1.7)$ & $49(4.1)$ & $15(1.6)$ & $7(0.7)$ & $1(0.1)$ \\
\hline
\end{tabular}


Case patients were matched with 2 comparison groups. First, we compared the amount of alcohol each injured patient consumed during the hours before injury with the same person's alcohol consumption during the same hours the previous day, using a case-crossover design. ${ }^{8}$ Second, we matched injured case patients from covered shifts with a population-based control group by age, sex, and residence (urban or rural). At the time of the interview, each control group participant was further matched to a specific case patient's injury event by day of week, and the interview then focused on the control participant's alcohol consumption before the matched case patient's hour of injury. Interviews were completed with 1,856 persons for a response rate of $47 \%$. The study was approved by the institutional review boards of all 3 participating hospitals.

\section{Measures}

We included injuries that had an identified time of occurrence and a mechanism in the E codes of the International Classification of Diseases, 9th Edition. We assessed injury severity with the Abbreviated Injury Scale (AIS), which rates severity in each of 6 body regions from 1 (minor) to $6 .{ }^{9}$ In $72 \%$ of cases, the highest AIS score was 1 ; therefore, we dichotomized injury severity into minor (AIS $=1$ ) and major (AIS >1). Injuries were judged intentional in $5 \%$ of cases.

Participants reported alcohol consumption by number of standard US alcoholic drinks (approximately $14 \mathrm{~g}$ ethanol: $12 \mathrm{oz}$ of beer, $5 \mathrm{oz}$ of wine, or $1.5 \mathrm{oz}$ of liquor) consumed in each hour during the 48 hours before injury or, for controls, before the matched reference time. The main analysis for the case-crossover study compared the amount of alcohol each person consumed during the 6 hours before injury with the amount they consumed during the same hours on the day before the injury. In the case-control analyses, we compared the amount of alcohol the case patient consumed during the 6 hours before injury with the amount the control participant consumed during the same 6 hours on a matched day of the week in a later week.

We defined hazardous alcohol consumption according to the per-occasion thresholds suggested by the National Institute on Alcohol Abuse and Alcoholism ${ }^{10}$ and based on empirical research ${ }^{11}$ : more than 4 drinks for men and more than 3 for women. Amounts less than these are usually considered nonhazardous; here, we label them low risk, keeping in mind that low risk does not necessarily mean no risk. We identified current alcohol use disorders using a structured interview ${ }^{12}$ and standard criteria. ${ }^{13}$

\section{Analyses}

Population attributable fraction (PAF) is the proportion of injuries that would not have occurred in the absence of the exposure-here, variables measuring alcohol consumption or alcohol use disorders. We used a standard formula for estimating PAF, ${ }_{1}^{4-16}$ which Greenland and Robins ${ }^{17}$ called excess fraction: the prevalence of the exposure among the cases, multiplied by the odds ratio minus 1 , divided by the odds ratio. The odds ratios were estimated by the ratio of discordant pairs in casecrossover analyses and by conditional logistic regression in case-control analyses. ${ }^{1}$ Case-crossover analyses used data from 2,517 injured case patients. Case-control analyses used the 2,161 case patients from covered shifts and their 1,856 matched community control participants. As shown in Table 1, case patients were more likely to have had alcohol in the 6-hour window.

\section{RESULTS}

\section{Case-Crossover Analyses}

In case-crossover analyses, the PAF that was due to alcohol consumption during the 6 hours before injury was $10.6 \%$ (Table 2). Low-risk drinking accounted for $43 \%$ of that PAF . Case-crossover analyses using 12 -

Table 2. Population Attributable Fraction (PAF) due to Alcohol Consumption During the Previous 6 Hours

\begin{tabular}{|c|c|c|c|c|}
\hline Level of Drinking & $\begin{array}{l}\text { Cases With This Level } \\
\text { of Consumption } \\
\text { No. (\%; } 95 \% \mathrm{Cl})\end{array}$ & OR* $(95 \% \mathrm{Cl})$ & $\begin{array}{c}\text { Stratum-Specific } \\
\text { PAF of Injuries* } \\
\%(95 \% \mathrm{Cl})\end{array}$ & $\begin{array}{l}\text { Total PAF } \\
\text { of Injuries } \\
\%(95 \% \mathrm{CI})\end{array}$ \\
\hline $\begin{array}{r}\text { Case-crossover analyses } \\
\text { (total cases }=2,510)\end{array}$ & & & & $10.6(7.8-13.5)$ \\
\hline Low-risk $^{\dagger}$ & $180(7.2 ; 6.2-8.2)$ & $2.7(2.0-3.8)$ & $4.5(3.1-6.0)$ & \\
\hline High-risk & $172(6.8 ; 5.9-7.9)$ & $9.5(5.2-17)$ & $6.1(4.8-7.4)$ & \\
\hline $\begin{array}{l}\text { Case-control analyses } \\
\text { (total cases }=2,161)\end{array}$ & & & & $8.6(5.7-11.5)$ \\
\hline Low-risk & $135(6.2 ; 5.3-7.4)$ & $2.0(1.4-2.8)$ & $3.1(1.5-4.7)$ & \\
\hline High-risk & $131(6.1 ; 5.1-7.2)$ & $10.8(5.6-21)$ & $5.5(4.2-6.8)$ & \\
\hline
\end{tabular}


hour windows on the day of injury and the day before gave similar findings.

Confidence intervals are shown in Table 2 both for the prevalence of the particular exposure among the case patients and for the odds ratios. Confidence intervals for the PAFs are estimated conservatively by using the lower bounds of prevalence and odds ratio to calculate the lower limit of the PAF, and the upper bounds of both for the upper limit of the PAF.

In subgroup analyses, the PAF that was due to alcohol consumption during the 6 hours before injury was greater for major injuries $(18.2 \%)$ than for minor injuries $(7.6 \%)$. The PAF that was due to low-risk drinking was substantially greater for major injuries $(9.9 \%)$ than for minor injuries (2.5\%). Among major injuries nonhazardous alcohol consumption accounted for more than one half the total PAF of short-term alcohol exposure.

The PAF that was due to alcohol consumption during the previous 6 hours was twice as great for men $(13.7 \%)$ as for women $(6.6 \%)$, but the proportion of each PAF that was due to low-risk drinking was similar ( $45 \%$ and $37 \%$, respectively). The PAF that was due to alcohol consumption during 6 the hours before injury was $2 \%$ for case patients older than 64 years, significantly less than the $15 \%$ to $23 \%$ for age-groups younger than 65 years.

\section{Case-Control Analyses}

The PAF that was due to alcohol consumption during the previous 6 hours was $8.6 \%$. Similar to case-crossover analyses, $36 \%$ of that was due to low-risk drinking. The PAF that was due to alcohol consumption during the 6 hours before injury was greater for major injuries (15.1\%) than for minor injuries $(6.6 \%)$. The PAF that was due to low-risk drinking was again greater for major injuries $(7.6 \%)$ than for minor injuries $(1.9 \%)$. As in case-crossover analyses, the PAF for men (10.8\%) was almost twice as great as for women (5.9\%), and the PAF for those older than 64 years $(2.2 \%)$ was significantly less than that for younger age-groups ( $8.5 \%$ to $22 \%$ ).

The PAF of past-year alcohol dependence (Table 3 ) was less than the PAF that was due to short-term alcohol exposure. The PAF for alcohol abuse was not calcu-

\section{Table 3. Population Attributable Fraction (PAF)} due to Current Alcohol Use Disorders

\begin{tabular}{|c|c|c|c|}
\hline Disorder & $\begin{array}{c}\text { Cases With Disorder } \\
(\mathrm{N}=2,161) \\
\text { No. }(\% ; 95 \% \mathrm{Cl})\end{array}$ & OR $(95 \% \mathrm{CI})$ & $\begin{array}{c}\text { PAF of Injuries } \\
\%(95 \% \mathrm{CI})\end{array}$ \\
\hline Alcohol abuse & 255 (11.8\%; Cl?) & $0.9(0.7-1.0)$ & $-^{*}$ \\
\hline Alcohol dependence & $178(8.2 \% ; 7.1-9.5 \%)$ & $1.9(1.5-2.6)$ & $4.0(2.2-5.8)$ \\
\hline
\end{tabular}

lated because the odds ratio was less than 1, yielding a negative PAF, which is meaningless.

\section{DISCUSSION}

In case-crossover and case-control analyses, $10.6 \%$ and $8.5 \%$, respectively, of all injuries could be ascribed to consuming alcohol during the preceding few hours. Approximately $40 \%$ of that PAF was due to consuming amounts that are generally considered safe. The PAF that was due to consuming alcohol during a few hours before injury and the proportion of that PAF due to low-risk drinking were greater for major injuries than for minor injuries in both case-crossover and case-control analyses.

Our findings are consistent with Kreitman's assertion that most alcohol-related harm occurs in those who are not alcoholic. ${ }^{5}$ The PAF that was due to alcohol dependence $(4.0 \%)$ was less than the PAF that was due to consuming alcohol during the 6 hours before injury $(8.5 \%$ to $10.6 \%)$, and alcohol abuse as defined by standard criteria was not associated with acute injury. Our findings are also consistent with what Stockwell and colleagues found ${ }^{6}$ : Most alcohol-associated injuries occurred in persons who had consumed a hazardous amount during the few hours before injury.

On the other hand, what is often considered moderate drinking is not totally safe. The PAF that was due to what is usually considered nonhazardous drinking was $4.5 \%$ in the case-crossover analysis and $3.1 \%$ in the case-control analyses, almost one half the total PAF that was due to alcohol consumption during the few hours before injury. About $4 \%$ of all injuries can be attributed to drinking an amount usually considered safe.

Few previous studies have estimated the PAF for injury caused by alcohol consumption. In a Greek casecontrol study comparing motor vehicle crash injuries with home and leisure injuries, Petridou and colleagues estimated a PAF of $10 \% .{ }^{18}$ In a time-series analysis of data from 1956 to 1994, Norström estimated the PAF of assault attributable to total alcohol consumption in the Swedish population was $47 \% .{ }^{19}$ In the developed regions of the world, alcohol-related PAFs of the total burden of disease, measured in disability-adjusted lifeyears, were $1.2 \%$ for intentional injury and $2.7 \%$ for unintentional injury. ${ }^{20}$ Our study is the first of which we are aware that estimates an alcohol attributable fraction for nonfatal injury across several mechanisms.

The formula we used to calculate PAF was first described by Miettinen ${ }^{14}$ and was called excess fraction by Greenland and Robins. ${ }^{17}$ Its calculation 
is appropriate only when a causal relationship exists and when changing the frequency of the exposure in the population is both attainable and, if attained, effective in reducing risk. ${ }^{21}$ We believe the relationship between consuming alcohol for a few hours and injury meets those criteria in theory.

The similarity of the case-crossover and case-control analyses, which used 2 separate comparison groups, strengthens the credibility of the findings. The higher PAF in the case-crossover analyses may be due to the inclusion of a larger number of more severely injured patients, among whom the PAF that was due to shortterm alcohol exposure was higher.

The current study used measures of short-term exposure that were temporally linked to the outcome. Some previous studies ${ }^{5,7}$ asked about any recent episode of heavy drinking. Stockwell and his colleagues ${ }^{6}$ asked about consumption on the day the outcome occurred, but by focusing their inquiry on problems associated with intoxication, they did not examine the risk associated with moderate drinking.

Addressing one criticism ${ }^{22}$ of previous studies of the prevention paradox, we examined the severity of the outcome. The PAF for low-risk drinking was greater among those with major injury $(9.9 \%$ in case-crossover analysis) than among those with minor injury (2.5\%). If the prevention paradox applies, it applies even more to more serious injuries.

Our study has several limitations. First, we studied only one alcohol-related outcome, injury requiring an emergency department visit. Even so, injury is a major cause of alcohol-related morbidity ${ }^{23}$ and mortality. ${ }^{24}$ Second, the study relied on retrospective self-report with potential for recall and other information bias. We have examined information bias in this study, ${ }_{1}^{25}$ however, and believe the 2 days of self-reported data used in these analyses are reliable. Third, all case patients were from hospitals in central Missouri, limiting generalizability. Fourth, the response rate among the community control group was low; however, the prevalence of episodic heavy drinking among control group participants was similar to that found in the Behavioral Risk Factor Surveillance Survey in Missouri, ${ }^{1,26}$ suggesting selection bias was unlikely to be substantial.

What is generally considered nonhazardous alcohol consumption is associated with injury. Consuming 2 or 3 alcoholic drinks for women, or 2 to 4 for men caused about $4 \%$ of all emergency department injury visits in this population-based study, about the same proportion as is caused by alcohol dependence. An even greater proportion of major injuries was attributable to these levels of drinking, between $7.6 \%$ and $9.9 \%$. In the United States in 2001, 29.2 million injuries were treated in emergency departments. ${ }^{27}$ Of those injuries, between
0.9 and 1.3 million are possibly attributable to drinking what has been considered a nonhazardous amount of alcohol. The potential benefit to individuals and society from preventing these injuries is considerable.

To read or post commentaries in response to this article, see it online at http://www.annfammed.org/cgi/content/full/3/1/47.

Key words: Alcohol drinking, wounds and injuries; population attributable fraction

Submitted December 1, 2003; submitted, revised, April 5, 2004; accepted April 292004.

A version of this report was presented at the North American Primary Care Research Group annual meeting, Banff, Alberta; October 27, 2003.

Funding support: The study was funded by a grant from the National Institute on Alcohol Abuse and Alcoholism (R01 AA11078). Additional support was provided by the Department of Family and Community Medicine at the University of Missouri-Columbia through the Opal Lewis Fund for alcohol research, and the Center for Family Medicine Science, which was supported by a grant from the American Academy of Family Physicians.

Acknowledgments: Malcolm Maclure, ScD, and Gordon Smith, MB, $\mathrm{ChB}, \mathrm{MPH}$, helped greatly with the design, analysis, and interpretation of the parent study. Nancy Mabe, MD, helped in the design of the preliminary study on which the current work built. Interviews of case patients were conducted by Carol Reidinger; Carey Smith; Ciprian Crismaru, MD; Amelia Devera-Sales, MD; Indira Gujral; Kari Gilmore; and Lindsay Wiles, Aneesh Tosh, Stephen Griffith, Darin Lee, Greg Morlin, and Rebecca Shumate, who were medical students at the time. Data management was by Sandy Taylor; Darla Horman; Robin Kruse, PhD; and Carol Reidinger.

Telephone interviews of control participants were conducted by Research Triangle Institute, Inc, Research Triangle Park, NC. We are very grateful to our colleagues in the emergency departments who helped make this study possible.

\section{References}

1. Vinson DC, Maclure M, Reidinger C, Smith GS. A population-based case-crossover and case-control study of alcohol and the risk of injury. J Stud Alcohol. 2003;64:358-366.

2. Rose G. Sick individuals and sick populations. Int J Epidemiol. 1985; 14:32-38.

3. Rose G. Strategy of prevention: lessons from cardiovascular disease. Br Med J. 1981;282:1847-1851.

4. Heller RF, Buchan I, Edwards R, Lyratzopoulos G, McElduff P, St Leger S. Communicating risks at the population level: application of population impact numbers. BMJ. 2003;327:1162-1165.

5. Kreitman N. Alcohol consumption and the preventive paradox. $\mathrm{Br}$ J Addict. 1986;81:353-363.

6. Stockwell T, Hawks D, Lang E, Rydon P. Unraveling the preventive paradox for acute alcohol problems. Drug Alcohol Rev. 1996;15:7-15.

7. Gmel G, Klingemann S, Muller R, Brenner D. Revising the preventive paradox: the Swiss case. Addiction. 2001;96:273-284.

8. Maclure M, Mittleman MA. Should we use a case-crossover design? Annu Rev Public Health. 2000;21:193-221.

9. Association for the Advancement of Automotive Medicine. Abbreviated Injury Scale: 1990 Revision. Des Plaines, III: Association for the Advancement of Automotive Medicine; 1990. 
10. National Institute on Alcohol Abuse and Alcoholism. Helping Patients with Alcohol Problems: A Health Practitioner's Guide. Washington, DC: U.S. Department of Health and Human Services; 2003.

11. Sanchez-Craig M. Empirically based guidelines for moderate drinking: 1-year results from three studies with problem drinkers. Am J Public Health. 1995;85:823-828.

12. Robins L, Cottler L, Bucholz K, Compton W. Diagnostic Interview Schedule for DSM-IV. St. Louis, Mo: Washington University School of Medicine, Department of Psychiatry; 1996.

13. American Psychiatric Association. Substance-related disorders. In: Diagnostic and Statistical Manual of Mental Disorders. Washington, DC: American Psychiatric Association; 1994:175-204.

14. Miettinen OS. Proportion of disease caused or prevented by a given exposure, trait or intervention. Am J Epidemiol. 1974;99:325-332.

15. Bruzzi P, Green SB, Byar DP, Brinton LA, Schairer C. Estimating the population attributable risk for multiple risk factors using case-control data. Am J Epidemiol. 1985;122:904-914.

16. Greenland S. Applications of stratified analysis methods. In: Rothman KJ, Greenland S, eds. Modern Epidemiology. Philadelphia, Pa: Lippincott-Raven; 1998:281-300.

17. Greenland S, Robins JM. Conceptual problems in the definition and interpretation of attributable fractions. Am J Epidemiol. 1988;128:1185-1197.

18. Petridou E, Trichopoulos D, Sotiriou A, et al. Relative and population attributable risk of traffic injuries in relation to blood-alcohol levels in a Mediterranean country. Alcohol Alcohol. 1998;33:502-508.
19. Norström T. Effects on criminal violence of different beverage types and private and public drinking. Addiction. 1998;93:689-699.

20. Ezzati M, Lopez AD, Rodgers A, Vander HS, Murray CJ, for the Comparative Risk Assessment Collaborating Group. Selected major risk factors and global and regional burden of disease. Lancet. 2002:360:1347-1360.

21. Rockhill B, Newman B, Weinberg C. Use and misuse of population attributable fractions. Am J Public Health. 1998;88:15-19.

22. Sinclair JD, Sillanaukee P. The preventive paradox: A critical examination. Addiction. 1993;88:591-595.

23. Wood M, Vinson DC, Sher KJ. Alcohol use and misuse. In: Blum A, Revenson T, Singer J, eds. Handbook of Health Psychology. Mahwah, NJ: Lawrence Erlbaum Associates; 2001:281-318.

24. Shultz JM, Rice DP, Parker DL. Alcohol-related mortality and years of potential life lost: United States, 1987. MMWR. 1990;39:173-178.

25. Vinson DC, Reidinger C, Wilcosky T. Factors affecting the validity of a timeline follow-back interview. J Stud Alcohol. 2003;64:733-740.

26. Division of Adult and Community Health. Behavioral Risk Factor Surveillance System Online Prevalence Data. Atlanta, GA: National Center for Chronic Disease Prevention and Health Promotion, Centers for Disease Control and Prevention. Available at: http://apps.nccd.cdc. gov/brfss/index.asp.

27. McCaig LF, Burt CW. National Hospital Ambulatory Medical Care Survey: 2001 Emergency Department Summary. Advance data from vital and health statistics; number 335. Hyattsville, MD: National Center for Health Statistics 2003 